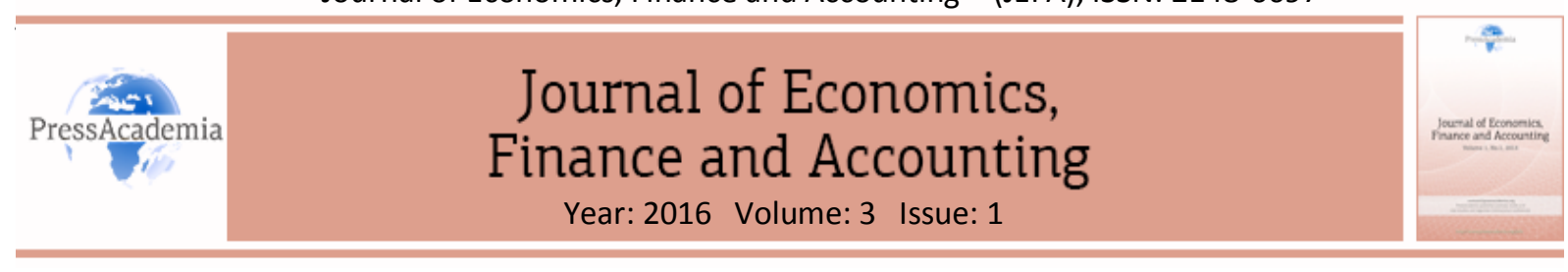

\title{
LAISSEZ-FAIRE LEADERS AND ORGANIZATIONS: HOW DOES LAISSEZ-FAIRE LEADER ERODE THE TRUST IN ORGANIZATIONS?
}

\section{DOI: 10.17261/Pressacademia.2016116538}

\author{
Hande Tosunoglu ${ }^{1}$, Ozge Tayfur Ekmekci ${ }^{2}$ \\ ${ }^{1}$ Hacettepe University. handetosunoglu@gmail.com \\ ${ }^{2}$ Hacettepe University. otayfur@hacettepe.edu.tr
}

\begin{abstract}
Supervisors are known to play significant role in instilling trust within the organizations. Following this corollary, the aim of this study is to investigate the effect of laissez-faire leadership on employees' trust in their organizations. Known as "absence of leadership", laissez-faire leadership is one of the ineffective and destructive leadership styles, which is assumed to erode the trust both in supervisors and organizations. Data were collected mostly from engineers (sample size $=129$ ) working in a public organization, conducting scientific and technological research on mineral exploration and geology. The finding including both correlation coefficients and results of structural equation modeling revealed that the experience of laissez-faire leadership by an immediate supervisor was strongly associated with reduced level of trust in organizations. More specifically, when a supervisor fails to satisfy to the expectations of subordinates by lack of presence and involvement, those behaviors seem to erode the employees' feelings of trust toward their organizations. This finding could be explained with the premises of psychological contract breach. Employees perceiving their supervisors reluctant or incompetent to satisfy their needs seem to lose their confidence that the organization would abide by the initial promises had been made, which wears away the trust in organization as time passes.
\end{abstract}

Key Words: Trust, organizational trust, leadership, laissez-faire leadership, ineffective leadership. JEL Classification: M10, M12, M54.

\section{INTRODUCTION}

Recent years have witnessed a surge of interest in the analysis of trust. Many studies tried to pinpoint the antecedents and correlates of trust, especially in organizational settings. This increased attention could be attributed to the impact of trust on gaining and sustaining competitive advantage. In a number of studies, trust was found to increase profitability, reduce turnover rates (Davis, Schoorman, Mayer, \& Tan, 2000), and enhance cooperation (Dirks \& Ferrin, 2001), commitment and motivation (Brockner, Daly, Martin, Siegel \& Tyler, 1997; Tyler, 2000). Despite these positive consequences and suggestions made to foster the trust, many organizations still suffer from lack of trust. Lazarus and Salem (2005) claimed that four in five employees had suspicions about the intentions of the organizations. Similarly, Reina and Reina (2007) reported that nine out of every 10 employees have reported experiencing some sort of breach of trust in the workplace on a regular basis. Given the fact that the feelings of distrust and cynicism could erode employee loyalty; thereby make employee retention difficult, new studies are needed to understand how management, particularly managers / leaders play a role in the development of trust.

The aim of this study is to investigate the effect of laissez-faire leadership on organizational trust using the data obtained from engineers in a Turkish public organization. So far, researchers focused mostly on constructive leadership styles such as authentic, ethical, transformational leadership style, although examples of destructive leadership are more prevalent in work life. As Skogstad, Einarsen, Torsheim, Aasland and Hetland (2007) noted empirical research on destructive leadership behaviors is relatively limited despite the plausible devastating 
consequences for subordinates and organization. Known as "absence of leadership" (Bass \& Avolio, 1990), laissez-faire leadership could be regarded as a special type of destructive leadership since laissez-faire leaders do not show interest in subordinates' needs, take decisions and give feedback on time. These leaders are not able to meet the legitimate expectations of their followers/ subordinates, therefore they are argued to create role conflicts, role ambiguities (Kelloway, Sivanathan, Francis \& Barling, 2005) and disagreements with coworkers (Skogstad et al., 2007). Although the destructiveness and negative side of laissez-faire leadership has been acknowledged by researchers, only limited number of studies (e.g., Kelloway et al., 2005; Skogstad et al., 2007) addressed the negative consequences of laissez-faire leadership on subordinates and organizations. This study aims to reveal whether experiencing laissez-faire leadership is associated with reduced levels of trust in organizations. In particular, the study addresses the plausible effect of absence of leadership on employee's confidence to their organizations. As indicated before, extant literature (e.g., Joseph \& Winston, 2005; Martins Marques de Lima Rua, \& Costa Araújo, 2013) has mostly focused on the effect of constructive leadership on employee's trust in supervisors and organizations. However, to our knowledge, only limited number of studies (e.g., Gillespie \& Mann, 2004) addressed the impact of destructive and passive leadership (including laissezfaire leadership) on trust. As Gillespie \& Mann (2004) noted, it is informative to understand common leadership practices that may adversely affect trust. Therefore revealing the effect of laissez-faire leadership on organizational trust could contribute to extant literature. This study could provide insights about how laissezfaire leadership is perceived and how it influences the organizational trust in Turkey, which is argued to differ from Western societies in terms of leadership practices accepted and enacted (see., Fikret-Pasa, Bodur \& Kabasakal, 2001). Turkish culture, characterized with high collectivism and power distance (Hofstede, 1980), supports paternalistic leadership, in which leader acts a like a father to the followers (Kabasakal \& Bodur, 1998). Studies investigating the leadership styles in Turkey reported that Turkish managers show parental consideration toward their subordinates (e.g., Aycan \& Fikret-Pasa, 2003), and exhibit nurturing and authoritarian behaviors at the same time. As in other countries, much of the interest has been devoted to investigate the prevalent leadership styles in Turkey; however less attention has been directed to the investigation of ineffective and destructive leadership styles like laissez-faire leadership. In one study, Pasa et al. (2001) found positive relationship between collectivist values and the prevalence of paternalistic and laissezfaire leadership styles in Turkish organizations. The researchers noted that laissez-faire leadership was not regarded as a desirable leadership style by Turkish employees. Following this corollary, it seems necessary to investigate how employees react to laissez faire leadership. By investigating the effects of laissez faire leadership on trust, this study aims to contribute existing literature.

In the following sections, firstly laissez-faire leadership and organizational trust will be explained, and then the relationship between these concepts will be discussed using theories and the results of existing studies. After this brief literature review, methodology and results of the study will be presented together with the implications of the results.

\section{LITERATURE REVIEW}

\subsection{Concept of Laissez-Faire Leadership}

The French term "laissez-faire" is mostly used in economics and political sciences to define a policy of minimum governmental interference in the economic affairs of individuals and society (Encyclopædia Brittannica, nd). In leadership literature, laissez-faire refers to a "hands-off, let things-ride" approach (Northouse, 2010) to influencing individuals in the workplace. Bass and Avolio (1990) describe laissez-faire leadership as "the absence of leadership" and "the avoidance of intervention". Laissez-faire leaders tend to behave as if they are abdicated from the responsibilities and duties assigned to him /her (Lewin, Lippit \& White, 1939). This leadership style resembles "impoverished management" detailed by Blake and Mouton (1985) by describing a leader exerting minimal effort to get required work done and showing minimal concern for subordinates (Einarsen, Aasland \& Skogstad, 2007). According to Lewin et al (1939), although laissez faire leaders have been nominated to leadership positions and physically occupy these positions, they ignore the responsibilities and duties assigned to them. Based on this, laissez-faire leadership should be regarded not only as "lack of presence", also as "zero leadership". 
Although Schyns and Schilling (2013) disagree with this claim, Einarsen et al (2007) regards laissez-faire leadership as a form of destructive leadership. Einarsen and colleagues (2007) argue that laissez-faire leadership violates the legitimate interests of the organizations and their employees by undermining organizational objectives and /or subordinates well-being. Bass and Avolio (1997) on the other hand, regards laissez-faire leadership as an ineffective leadership style together with active corrective leadership (leading by monitoring and focusing on mistakes) and passive corrective leadership (waiting for things to go wrong before intervening).

\subsection{Concept of Organizational Trust}

The "trust" literature is plagued by an abundance of definitions, which seem to make the defining features and dimensions of trust are still open to debate. So far, the concept of trust has been defined by different disciplines such as sociology, psychology and administrative sciences. Most cited definitions of trust, however, seem to share some conceptual and linguistic commonalities. Most conceptualizations of trust emphasize risk or vulnerability (Rousseau, Sitkin, Burt, \& Camerer, 1998). For example, Mayer, Davis and Schoorman (1995) define trust as "the willingness of a person to be vulnerable to the actions of fellow coworkers whose behavior and actions that person cannot control." (p.709). Similarly, Doney, Cannon and Mullen (1998) conceptualize trust as "willingness to rely on another party and to take action in circumstances where such action makes one vulnerable to the other party"(p.604). Based on the discussions in the literature, one can assume that trust exists when one party is willing to make themselves vulnerable to the discretionary behavior of other party (Pirson \& Malhotra, 2010).

In the early studies, trust has mostly been studied at a general level without acknowledging the different referents. However as Dirks and Skarlicki (2004) point out, identification of the different referents of trust such as organizational, supervisory or coworker trust enables organizations to better leverage the benefits of trust given the fact each type of trust has its own unique antecedents and consequences. Acknowledging the differences in referents of trust, researchers have started to analyze coworker, organizational and supervisor trust separately. In this study, we will focus on organizational trust, which could argued to be different from supervisor or coworker trust in terms of abstraction level. Like other referent of trust, many definitions of organizational trust have been offered. For example, Schoorman, Mayer, and Davis (2007) conceptualize organizational trust (i.e., trust in an organization) as "employees' willingness to be vulnerable to their organization's actions or policies". In a way, organizational trust represents employees' confidence and expectations about the actions of their organization (Lin, 2010).

The existence of trust in organization has been reported to be associated with number of positive outcomes. Conversely, the absence or loss of organizational trust usually results in the loss of highly qualified employees to other organizations, a loss of interest among employees in the job and organization, and increased levels of absenteeism and tardiness (Kowalski \& Cangemi, 1993; cited in Hollander Vineburgh, 2010). Besides that as Currall and Epstein (2003) argue, it is almost impossible for organizations to regain trust once it has been lost. Trust has become a rare resource, which every organization should strive to obtain and maintain in today's business world. Therefore, understanding the development of trust within the organization has gained utmost importance in the last decades.

\subsection{Relationship between Laissez-Faire Leadership and Organizational Trust}

Leaders or managers are believed to play primary role in establishing and developing trust in organizations (e.g., Creed, Miles, Kramer \& Tyler, 1996; Fairholm, 1994; McAllister, 1995). As Lewin (1999) pointed out leaders / managers could create culture of trust by creating sense of credibility (i.e., doing what they say they are going to do) and showing consistency (i.e., behave in a predictable way). It is also argued that some leader behaviors such as clarifying shared purpose, direction and vision, providing frequent and timely communication and ensuring high quality interpersonal relationships enable the development of culture of trust (Cufaude, 1999). Furthermore, leaders were found to build trust in organizations by making their positions clearly known, supporting the employees and articulating and consistently implementing a particular direction (Northhouse, 2011). 
Although effective leadership enables the development of trust within the organizations, the other side of the coin is also possible. Burris, Deter and Chiaburu (2008) claim that negative feelings toward the supervisor could spill over to the feelings toward the organization, thereby make feelings and attitudes about organization negative. This claim could be reasonable because employees perceive their supervisor as the representative of their organization, which may lead them to generalize the negative feelings toward him/her to organization. Besides that working with undesirable, incompetent or destructive supervisors could create perception among employees that the organization does not intervene to protect themselves (Schyns \& Schilling, 2013). Day by day, such negative feelings could erode the trust in organizations. In line with above arguments, Gillespie and Mann (2004) reported negative relationship between laissez-faire leadership and trust in supervisors, which is argued to be closely associated with trust in organizations. The researchers claims that, through their avoidance of taking an active leadership role, passive and laissez-faire leaders lose the opportunity to build trust of their followers or even such a trust already exits, this ineffective leadership erodes that trust as the time passes.

The concept of psychological contract (Rousseau, 1989) could explain the plausible relationship between laissez-faire leadership and trust, including trust in organizations. Psychological contract reflects an individual's beliefs about the terms and conditions of a reciprocal exchange agreement between that person and another party (Rousseau, 1989). If employees perceive that their organizations or supervisors fail to fulfill the promised obligations, they experience a psychological contract breach (Rousseau, 1989; cited in Robinson, 1996), which could adversely affect their job satisfaction and commitment. According to Rousseau (1989), psychological contract breaches results in erosion of trust by undermining two important foundations of trust. Integrity, which reflects "perceived consistency of another's actions and the extent to which another's actions are congruent with his /her word" (Mayer et al, 1995, p.719), constitutes one of the key elements of trust. According to Robinson (1996), when employee perceives an inconsistency between the managers' words and actions, that is $s /$ he thinks that manager is lack of integrity, $s /$ he loses confidence that the contributions made today will be reciprocated by the organization in the future. By failing to fulfill the promised obligations (i.e., not showing concern for employees, not providing guidance), laissez-faire leaders or managers could seem inconsistent to employees, which would undermine judgments about their integrity and cause psychological contract breaches. As a result, employees' trust in both managers and organizations could erode. In addition to perceived integrity, psychological contract breaches give damage to interpersonal relations by raising question marks about perceived benevolence of supervisors or management. When leaders / supervisors violate psychological contracts, they undermine "respect" and "concern for one's welfare", which constitute building blocks of any trusting relations. By showing no benevolence and effort to enhance the welfare of their subordinates, laissez-faire leaders/supervisors could violate the psychological contract between employees and organizations; which could result in loss of trust in both themselves and organizations.

The arguments about psychological contract breach and its plausible effects on trust together with the empirical findings showing leaders' / managers' play primary role in establishing and developing trust in organizations (e.g., Creed, Miles, Kramer \& Tyler, 1996; Fairholm, 1994; McAllister, 1995) lead us to hypothesize:

Hypothesis: Experiencing laissez-faire leadership by one's immediate superior/supervisor is associated with lower levels of trust in organizations.

\section{METHOD}

\subsection{Participants and Procedure}

In this study, data were collected from a Turkish public organization, conducting scientific and technological research on mineral exploration and geology. Although the organization employs both white and blue collar employees, only white collar employees, mostly engineers were included to the study. We preferred this sample group because the participants were working at teams, having designated team leaders. We believe that people working at team- based structure are in a better position to assess the leadership style of their supervisors or leaders. 
Before data collection, aims of the study were introduced to participants. Confidentiality and anonymity of their answers were ensured in order to eliminate the concerns about evaluating their supervisors. Employees willing to give sincere responses were asked to take part in study; therefore no incentives were offered to ensure higher participation. The data collection was based on convenience, meaning that people who were present at the time of data collection took part in the study. Out of one hundred fifty questionnaires, one hundred twenty nine questionnaires were returned (response rate: 86\%). However, one questionnaire form was excluded from the analyses because of the high number of missing answers.

Majority of the participants were male $(n=92 ; 72 \%)$, married ( $n=93 ; 73 \%)$ and highly educated (having mostly undergraduate: $63 \%$ and graduate degrees: $35 \%$, only $2 \%$ high school degree). Approximately $36 \%$ of the participants were between 26-35; 24\% between 36- 45 and \% 28 between 46-55 years old. They were working in engineering and managerial positions (67\%), while the remaining ones were working in other positions (23\%). Most participants stated that they were working with their current supervisors more than one year (82.8 $\%)$; therefore they were in a position to assess the leadership style of their supervisors.

\subsection{Measures}

In the self-report survey, we asked participants to evaluate items related to organizational trust, laissez-faire leadership and demographics. Demographic information (i.e., marital status, gender, education level, tenure, position, working time with supervisor) was asked to understand the participants' profile and control for their plausible effects on organizational trust.

Organizational Trust: In this study, organizational trust was measured with 12 item Organizational Trust Inventory developed by Nyhan and Marlowe (1997) and 4-item inventory developed by Cummings and Bromiley (1996). Items measure people's confidence to their organization about its willingness to act according to their interests. Sample item was "I think people in this organization tell the truth in negotiations". Respondents rated 7-point Likert scale ranging from "strongly disagree (1)" to "strongly agree (7)" with higher scores indicative of higher level of trust in organizations. As it can be seen from Table XXX, the reliability of the scale $(\alpha=.91)$ was well above the criteria suggested by Nunnally (1978).

Laissez-Faire Leadership: Laissez faire leadership behavior was measured using 4-items from Multifactor Leadership Questionnaire of Bass and Avolio (1990). Sample items were: "Has avoided telling me how to perform my job"; "Has steered away from showing concern about results". Responses to items are measured on a 5-point scale (not at all, once in a while, sometimes, fairly often, frequently if not always) in which higher scores are indicative of higher level of laissez-faire leadership. The reliability of the scale $(\alpha=.81)$ was found to be satisfactory.

\subsection{Analyses}

In this study, full-structural equation modeling was used to analyze the structural relationship between measured variables (i.e., questionnaire items) and latent constructs (organizational trust and laissez-faire leadership). This modeling technique enables researchers to combine confirmatory factor analysis and multiple regression analyses by testing measurement and structural models simultaneously. Through measurement model, confirmatory factor analysis (CFA) was conducted to determine whether the number of factors (i.e., constructs) and the loadings of the items in the questionnaire were in line with the two-factor structure. After examining the factor structure, hypothesized relation between trust and laissez-faire leadership was tested through structural model. All analyses were conducted with AMOS 17 (Arbuckle, 2008), which provides maximum likelihood parameter estimates of specified paths (relations) and several indices of fit (i.e., chi square ratio, goodness of fit index-GFI, comparative fit index-CFI, root mean square approximation-RMSEA).

The significance of factor loadings and hypothesis was assessed by means of standardized estimates and $t$ values. Degree of fit between model and data was examined with the robust statistics (i.e., chi square, chi square ratio, CFI, GFI and RMSEA). Although insignificant chi-square $\left(\chi^{2}\right)$ value is considered as a sign of good fit, Bryne (1998) suggests researchers to accept small $\chi^{2}$ value (relative to its degrees of freedom) as an indication of good fit, considering the sensitivity of $\chi^{2}$ value to sample size. Following the suggestion of Schermeller, Moosbrugger, and Müller, (2003), $\chi 2 / \mathrm{df}$ values between 0 and 2 were accepted as an indication of 
good fit; between 2 and 3 as an indication of acceptable fit. For CFI, values of greater than .90 were initially regarded as indication of good fit (Bentler, 1990), however, recently a value exceeding this cut off was suggested in order to prevent Type I error (i.e., ensure that mispecified models are not accepted) (Hu and Bentler, 1999). For the other criterion, RMSEA, values of less than .05 were considered evidence of a good fit, between .05 and .08 a fair fit, between .08 and .10 a mediocre fit, and greater than .10 a poor fit (MacCallum, Browne, \& Sugawara, 1996).

\section{RESULTS}

\subsection{Results of Preliminary Analysis}

Before proceeding to main analysis, organizational trust and laissez-faire leadership were examined for accuracy of data entry, missing values and normality. Firstly, missing values were replaced with mean of respective items. Secondly, univariate and multivariate normality were assessed with Kolmogorov -Smirnov and Mardina coefficient tests respectively and no severe violations of normality were detected.

After aforementioned data screening, we examined the reliability estimates. The internal consistency of the items was found to be satisfactory for laissez-faire leadership (Cronbach's $\alpha=.81$ ). For organizational trust, however, four items were found to decrease internal consistency. It was realized that these four items were all negatively worded items. In order not to experience problems, these items were excluded from the further analyses. With the remaining items $(n=11)$, trust scale turned out to be highly reliable (Cronbach's $\alpha=.91$ ). After reliability analysis, we computed the composite scores by taking the mean of the responses to trust and laissez-faire items. By using these composite scores, we examined the correlations between study variables and demographics (see Table 1 for correlations). Neither trust nor laissez-faire leadership was found to be significantly related to demographic variables (i.e., gender, age, marital status, tenure and amount of years working with current supervisor). Consistent with the expectation, laissez-faire leadership and organizational trust was found to be negatively correlated $(r=-.49, p<.01)$.

Table 1: Descriptive Statistics of Study Variables

\begin{tabular}{lllllllllll}
\hline & Mean & SD & $\alpha$ & 1 & 2 & 3 & 4 & 5 & 6 & 7 \\
\hline 1. Gender & -- & -- & -- & 1 & & & & & & \\
2.Age & -- & -- & -- & $.17^{*}$ & 1 & & & & \\
3.M.Status & -- & -- & -- & -.03 & $.28^{* *}$ & 1 & & & & \\
4.Tenure & -- & -- & -- & .12 & $.67^{* *}$ & $.23^{* *}$ & 1 & & & \\
5.W.T.Sup & -- & -- & -- & .08 & $.33^{* *}$ & $.27^{* *}$ & $.39 * *$ & 1 & & \\
6.L.F.Leader & 1.45 & 3.84 & .81 & .11 & .02 & -.08 & .01 & -.01 & 1 & \\
7.Trust & 1.04 & 1.27 & .91 & -.06 & .03 & .11 & -.06 & .06 & $-49^{* *}$ & 1 \\
\hline
\end{tabular}

Note. Gender: 1=Women; $2=$ Men; Age: $1=18-25$ years ; $2=26-35$ years; 3= 36-45 years; $4=46-55$ years; $5=56$ and above years. M. Status: $1=$ Single; $2=$ Married; Tenure: $1=$ less than $1 ; 2=1-3$ years; $3=4-7$ years; $4=8-12$ years; $5=13-18$ years; $6=19-25$ years; $7=26$ and above. Working Time with Supervisor (W.T.Sup): 1= less than 1; $2=1-2$ years; 3= 3-5 years; $4=$ more than 5 years. Laissez Faire Leadership (L.F.Leader): Measured with 5-point scale; Trust: Measured with 7-point scale. *: significant at .05 level; ${ }^{* *}$ significant at .01 level.

\subsection{Results of Main Analysis}

As indicated before, we used full-latent modeling, which includes both measurement and structural models. In measurement model part, two latent variables (i.e., laissez-faire leadership and trust) were hypothesized to be measured with 15 items and these latent variables were not allowed to co-vary. Initial results indicated poorfitting model $(\chi 2(89)=218.11, \mathrm{p}<.05 ; \chi 2 / \mathrm{df}=2.45 ; \mathrm{CFI}=.87 ; \mathrm{GFI}=.83$, RMSEA =.11). The modification indices suggest adding covariances between error terms of trust items. Since these items were supposed to measure same construct (i.e., trust), six error covariances were added to the model. After this modification, the model improved substantially as evidenced by significant chi-square change $(\Delta \chi 2(6)=88.14 ; p<.01)$. Revised model had an acceptable level of fit to the data $(\chi 2(83)=129.97, p<.05 ; \chi 2 / d f=1.57 ; \mathrm{CFI}=.95 ; \mathrm{GFI}=.89, \mathrm{RMSEA}$ $=.07)$. 
After assessing model fit, the pattern of factor loading was examined using parameter estimates As seen in Table 2, all items loaded satisfactorily on their respective factors, meaning that the item and construct relations turned out to be as expected. After assuring that items were able to measure organizational trust and laissezfaire leadership, the significance of hypothesized relation was examined. As hypothesized, laissez-faire leadership positively predicted the organizational trust $(B=-.56 ; p<.01)$, rendering the study hypothesis supported.

Table 2: Results of Full Latent Modeling

\begin{tabular}{llll}
\hline Path from_to & B & SE (b) & $\boldsymbol{\beta}$ \\
\hline Trust to T1 & .78 & .14 & $.52^{* *}$ \\
Trust to T2 & .92 & .14 & $.63^{* *}$ \\
Trust to T3 & .96 & .13 & $.68^{* *}$ \\
Trust to T4 & 1.14 & .15 & $.72^{* *}$ \\
Trust to T5 & 1.15 & .13 & $.80^{* *}$ \\
Trust to T6 & .67 & .13 & $.48^{* *}$ \\
Trust to T7 & 1.12 & .14 & $.75^{* *}$ \\
Trust to T8 & 1.16 & .14 & $.76^{* *}$ \\
Trust to T9 & 1.20 & .14 & $.80^{* *}$ \\
Trust to T10 & .73 & .12 & $.51^{* *}$ \\
Trust to T11 & 1.00 & -- & $.72^{* *}$ \\
LFL to LFL1 & 1.39 & .20 & $.78^{* *}$ \\
LFL to LFL2 & 1.20 & .17 & $.80^{* *}$ \\
LFL to LFL3 & 1.04 & .17 & $.66^{* *}$ \\
LFL to LFL4 & 1.00 & -- & $.66^{* *}$ \\
L.F.Leadership >>Trust & $-.83^{* *}$ & .18 & $-.56^{* *}$ \\
\hline
\end{tabular}

Note. LFL: Laissez-faire leadership. ${ }^{* *}$ significant at .01 level.

Since the sample size was relatively small, we conducted bootstrapping analysis to verify aforementioned results. The bootstrap estimates presented in Table 3, were based on 1000 bootstrap samples. As seen from the table, none of the percentile confidence intervals included zero, which supported our conclusion that the effect of laissez-faire leadership on organizational trust was significant at the .05 level. Besides confidence intervals, AMOS reported significant $p$-values for the bias corrected bootstrap method. The bootstrapping results confirmed the findings of path analysis mentioned above.

Table 3. Results of Bootstrapping

\begin{tabular}{lllllll}
\hline & \multicolumn{3}{c}{ Bias Uncorrected 95\% Cl } & \multicolumn{3}{l}{ Bias Corrected 95 \% Cl } \\
\hline Path from_to & Lower & Upper & $\underline{\mathbf{p}}$ & Lower & $\underline{\text { Upper }}$ & $\underline{\mathbf{P}}$ \\
LF leadership toTrust & -.70 & -.39 & .002 & -.70 & -.39 & $.002^{*}$ \\
Trust to T1 & .34 & .65 & .002 & .35 & .66 & $.001^{*}$ \\
Trust toT2 & .52 & .74 & .002 & .52 & .74 & $.002^{*}$ \\
Trust toT3 & .57 & .77 & .002 & .57 & .77 & $.003^{*}$ \\
Trust toT4 & .58 & .82 & .002 & .59 & .82 & $.001^{*}$ \\
Trust toT5 & .69 & .88 & .002 & .69 & .88 & $.003^{*}$ \\
Trust toT6 & .29 & .64 & .002 & .29 & .63 & $.003^{*}$ \\
Trust toT7 & .63 & .84 & .002 & .62 & .83 & $.003^{*}$ \\
Trust toT8 & .65 & .85 & .002 & .64 & .85 & $.003^{*}$ \\
Trust toT9 & .71 & .88 & .002 & .70 & .87 & $.004^{*}$ \\
Trust toT10 & .34 & .65 & .002 & .35 & .65 & $.001^{*}$ \\
Trust toT11 & .61 & .82 & .002 & .61 & .82 & $.002^{*}$ \\
LFL to LFL1 & .67 & .89 & .002 & .66 & .88 & $.003^{*}$ \\
\hline
\end{tabular}




\begin{tabular}{lllllll}
\hline LFL to LFL2 & .68 & .90 & .002 & .67 & .90 & $.002^{*}$ \\
LFL to LFL3 & .49 & .80 & .002 & .47 & .80 & $.003^{*}$ \\
LFL to LFL4 & .49 & .78 & .002 & .48 & .77 & $.003^{*}$ \\
\hline
\end{tabular}

Note: All values are standardized estimates. $\mathrm{Cl}$ : confidence interval. ${ }^{*}$ significant at .01 level based on 1000 bootstrap samples

\subsection{Discussion}

The main aim of this study is to investigate the effect of laissez-faire leadership on organizational trust. To our knowledge, empirical studies have not studied the relationship between laissez-faire leadership and organizational trust so far. However, a number of empirical studies have reported relatively strong relationship between constructive leadership styles (i.e., transformational leadership and ethical leadership) and trust in organizations. Since the absence of constructive leadership and associated behaviors could suggest the existence of laissez-faire leadership, we expected to obtain negative relation between laissez-faire leadership and organizational trust. In line with this expectation, the experience of laissez-faire leadership by an immediate supervisor was strongly associated with reduced level of trust in organizations. Both correlation coefficients and results of structural equation modeling support the assumption that when a supervisor fails to satisfy to the expectation of subordinates by lack of presence and involvement, these behaviors may erode the trust employees feel toward their organizations. Being the representative of the organization, supervisors' lack of consideration seems to be regarded by employees as reflection of organizations' indifferent approach to themselves. Negative perceptions regarding the organizations, in turn, manifest itself as lack of trust in these organizations. As Burris et al (2008) claim, negative feelings toward the supervisors seem to spill over to the feelings toward the organizations, thereby erode the confidence in those organizations.

The negative effect of laissez-faire leadership on organizational trust seems to support the arguments of Einarsen et al. (2007) about the destructiveness of laissez-faire leadership. As the researchers asserted, it seems that leaders fail to support the legitimate interests of organizations and employees by ignoring the responsibilities and duties assigned to them and showing little or no concern for employees' wellbeing. Employees seem to perceive this inactive, ignorant and ineffective leadership as a sign of psychological contract breach, such that organization failed to fulfill the promised obligations. As Robinson (1998) argues, the trust in management and organization erodes in response to contract breaches because employees question the benevolence and integrity of management.

\section{CONCLUSION}

Shockley-Zalabak et al. (2000) argue that organizations with high levels of internal trust are more successful, adaptive and innovative than organizations with low level of trust or characterized with distrust. Given the fact that trust is mostly depended on supportive behaviors of leader or managers (Gimbel, 2001; Tschannen-Moran \& Hoy, 1998), leadership training and development programs should be designed to equip leaders with the skills to follow more active leadership. In training programs, the leaders or managers should be informed about the importance of satisfying legitimate interests of the organizations and its stakeholders, especially the interests of employees. By giving timely feedback and decisions, using fair procedures and rewards, managers could follow more active leadership and as a result gain the trust of the employees both for themselves and the organization.

While interacting with employees and designing organizational procedures, giving special attention to three primary antecedents of trust (i.e., ability, benevolence and integrity) could be a good starting point for cultivating culture of trust. Managers could promote perceptions of "benevolence" by showing genuine concern for employees' concerns. For instance, rather than establishing reward structures characterized with "zero sum games", managers could distribute monetary and non-monetary rewards based on collaboration and performance, which would enhance perception of fairness and benevolence. Besides that by providing credible and honest information regarding their intentions and abilities, managers could portray more positive image regarding their proficiency and competency. Acting as the representative of the organization, reputable, credible and competent managers are in a better position to instill trust in organizations. In addition to establishing credibility and showing benevolence, managers are advised to be consistent in their words and actions, keep their promises and create transparency within the organizations. By not violating psychological 
contracts and being consistent, managers could evoke positive image regarding their integrity, which is argued to be basis of any trusting relationship.

However, it should be acknowledged that the study has some conceptual and methodological limitations, which cast doubt about the external and internal validity of the findings. Conceptually, the nature and number of variables included in this study provided limited perspective regarding the development of organizational trust. It should be acknowledged that our study focuses only on the influence of laissez-faire leadership although trust-building could be associated with variety of organizational, relational, or individual factors (Doney \& Cannon, 1997; McAllister, 1995). In future studies, researchers are advised to investigate the effects of individual (i.e., propensity to trust, agreeableness) and organizational level variables (i.e., organizational culture) to provide more complete picture of organizational trust. For example future research may contribute the existing literature by studying the moderating effects of "personality" and other individual difference variables such as demographics and tenure. Addressing the moderations would be helpful for gaining deeper understanding of trust formation within the organizations. Furthermore, this study focused only on organizational trust; therefore the findings may not be generalized to supervisory or coworker trust, which are argued to have different antecedents (Dirks \& Skarlicki, 2004). Therefore we suggest researchers to examine the same hypotheses for different referents of trust such as supervisor, organization and subordinate.

Other than aforementioned conceptual limitations, methodological limitations should also be acknowledged. The first methodological limitation is related to research design. This study is a snapshot study that measure trust and leadership perceptions at a single point in time. Although snapshot studies give important insights about hypothesized relations, they provide limited knowledge about the development of a particular variable over time. Unfortunately, in this study, we could not uncover how and why people feel trust toward their organizations. Therefore, we suggest the researchers to use longitudinal designs to reveal how leadership style influences trust development over time.

The second methodological limitation may stem from self-report data collection and cross sectional research design. We collected the data from same employees at single point in time. Although Harman's one-factor test and structural equation modeling demonstrated the distinctiveness of the constructs (i.e., variables), it is impossible to preclude the possibility of common method variance problem arising from self-report data collection and cross sectional research design. Common method variance problem could have inflated the correlations between variables and erroneously lead to infer a substantive relationship (Podsakoff \& Organ, 1986). Several remedies such as data collection from different sources at different times or escalating the unit of analysis could have taken to rule out this problem and increase the validity of the results (See Podsakoff \& Organ, 1986; Podsakoff, MacKenzie, Lee \& Possakoff, 2003, for details).

Despite its limitations, this study is a step towards a deeper understanding of how to build organizational trust through effective leadership. The findings of the present study support the belief that ineffective leadership erodes employee's trust in organizations. We believe by using the findings of this study, managers/leaders could cultivate culture of trust by using more active and employee-centered leadership.

\section{REFERENCES}

Arbuckle, J. 2008, “Amos 17.0 user's guide”. Spring House, PA: AMOS Development Corporation.

Aycan, Z., \& Fikret-Pasa, S. 2003. "Career choices, job selection criteria, and leadership preferences in a transitional nation: The case of Turkey" Journal of Career Development, Vol.30, no.2, pp.129-144.

Bass, B. M., \& Avolio, B. J. 1990, "Transformational leadership development: Manual for the multifactor leadership questionnaire”, Palo Alto, CA: Consulting Psychologists Press.

Bass, B. M., \& Avolio, B. J. 1997, "Full range leadership development: Manual for the Multifactor Leadership Questionnaire"(pp. 43-44). Palo Alto, CA: Mind Garden.

Bentler, P. M. 1990, “Comparative fit indexes in structural models”, Psychological bulletin, Vol.107, no.2, pp.238-246. 
Blake, R. R., \& Mouton, J. S. 1985, "The managerial grid III: a new look at the classic that has boosted productivity and profits for thousands of corporations worldwide", Oxford: Butterworth-Heinemann.

Brockner, J., Siegel, P. A., Daly, J. P., Tyler, T., \& Martin, C. 1997, “ When trust matters: The moderating effect of outcome favorability", Administrative Science Quarterly, Vol.42, no.3, pp. 558-583.

Burris, E. R., Detert, J. R., \& Chiaburu, D. S. 2008, “Quitting before leaving: the mediating effects of psychological attachment and detachment on voice", Journal of Applied Psychology, Vol.93, no.4, pp.912-922.

Byrne, B. M. 1998, "Structural Equation Modeling: Basic Concepts, Application, and Programming", Lawrence Earlbaum Associated. Inc., Mahwah, NJ.

Creed, W. D., Miles, R. E., Kramer, R., \& Tyler, T. 1996, “Trust in organizations”, In R. M. Kramer \& T. R. Tyler (Eds.), Trust in organizations: Frontiers of theory and research (pp. 16-38), Thousand Oaks, CA:Sage.

Cufaude, J. 1999, “Creating Organizational Trust: Defining, establishing, and maintaining something as elusive and fragile as trust is as difficult as it is essential", Association Management-Washington-, 51, 26-36.

Cummings, L.L., \& Bromiley, P. 1996, “The Organizational Trust Inventory (OTI): Development and validation”. In R. M. Kramer \& T. R. Tyler (Eds.), Trust in organizations: Frontiers of theory and research (pp. 302-330), Thousand Oaks, CA:Sage.

Currall, S. C., \& Epstein, M. J. 2003, "The fragility of organizational trust:: Lessons from the rise and fall of Enron", Organizational Dynamics, Vol. 32, no.2, pp.193-206.

Davis, J. H., Schoorman, F. D., Mayer, R. C., \& Tan, H. H. 2000, “ The trusted general manager and business unit performance: Empirical evidence of a competitive advantage", Strategic Management Journal, Vol. 21, no.5, pp.563-576.

Dirks, K. T., \& Ferrin, D. L. 2001, “The role of trust in organizational settings”, Organization Science, Vol.12, no.4, pp. $450-467$.

Dirks, K. T., \& Skarlicki, D. P. 2004, "Trust in leaders: Existing research and emerging issues. In R. Kramer \& K. Cook (Eds), Trust and distrust in organizations: Dilemmas and approaches, (pp.21-40), Russell Sage Foundation.

Doney, P. M., Cannon, J. P., \& Mullen, M. R. 1998, "Understanding the influence of national culture on the development of trust", Academy of Management Review, Vol.23, no.3, pp.601-620.

Einarsen, S., Aasland, M. S., \& Skogstad, A. 2007, "Destructive leadership behaviour: A definition and conceptual model", The Leadership Quarterly, Vol.18, no:3, pp.207-216.

Fairholm, G. W. 1994, "Leadership and the Culture of Trust”, Greenwood Publishing Group.

Fikret Pasa, S., Kabasakal, H. \& Bodur, M. 2001," Society, Organisations, and Leadership in Turkey. Applied Psychology:An International Review, Vol. 50, pp. 559-589. doi: 10.1111/1464-0597.00073

Gillespie, N. A., \& Mann, L. 2004, "Transformational leadership and shared values: The building blocks of trust", Journal of Managerial Psychology, Vol.19, no.6, pp.588-607.

Gimbel, P.A. 2001, "Understanding principal trust-building behaviors: evidence from three middle schools", Dissertation Abstracts International, UMI No. 3018320.

Hofstede, G. 1984. "Culture's consequences: International differences in work-related values”, Thousand Oaks, CA: Sage.

Hollander Vineburgh, J. 2010, "A Study of Organizational Trust and Related Variables Among Faculty Members at HBCUs", Theses and Dissertation, University of lowa.

Hu, L.T. and Bentler, P.M. 1999, "Cutoff criteria for fit indexes in covariance structure analysis: Conventional criteria versus new alternatives", Structural Equation Modeling, Vol.6, no.1, pp.1-55.

Joseph, E. E., \& Winston, B. E. 2005, “A correlation of servant leadership, leader trust, and organizational trust", Leadership \& Organization Development Journal, Vol.26, no.1, pp. 6-22.

Kabasakal, H. \& Bodur, M. 1998,"Leadership, values, institutions: The case of Turkey", Research Papers, Bogazici University, Istanbul, turkey.

Kelloway, E. K., Sivanathan, N., Francis, L., \& Barling, J. 2005. “Poor leadership”, Handbook of work stress, pp. 89-112, Retrieved from http://web.business.queensu.ca/faculty/julianbarling/BooksChapters/Poor\%20Leadership.pdf

Kowalski, C.J. \& Cangemi, J.P. 2005, “Developing trust and distrust in higher education”, In Cangemi, J.P., Kowalski, C.J., Miller, R.L., and Hollopteter, T.W., eds, Developing Trust in Organizations, McGraw-Hill, Boston, MA, pp 203-214. 
Lazarus, H., \& Salem, M. 2005, "Trust, distrust, and their implications for decision making and profit", Developing Trust in Organizations, McGraw-Hill, Boston, MA, 45-50.

Lewin, K., Lippitt, R., \& White, R. K. 1939, "Patterns of aggressive behavior in experimentally created "social climates", The Journal of Social Psychology, Vol.10, no.2, pp. 269-299.

Lewin K. 1999, "The complete social scientist", In: Gold M (ed) A Kurt Lewin Reader. New York: American Psychological Society Press

Lin, C. P. 2010, "Modeling corporate citizenship, organizational trust, and work engagement based on attachment theory", Journal of Business Ethics, Vol.94, no.4, pp.517-531.

MacCallum, R. C., Browne, M. W., \& Sugawara, H. M. 1996, “Power analysis and determination of sample size for covariance structure modeling", Psychological Methods, Vol. 1, no.2, pp. 130-149.

Martins Marques de Lima Rua, O. M., \& Costa Araújo, J. M. 2013, "The influence of the transformational leadership in the organizational trust", Harvard Deusto Business Research, Vol.2, no.1, pp. 55-66.

Mayer, R. C., Davis, J. H., \& Schoorman, F. D. 1995, “An integrative model of organizational trust”, Academy of Management Review, Vol. 20, no.3, pp. 709-734.

McAllister, D. J. 1995, "Affect-and cognition-based trust as foundations for interpersonal cooperation in organizations", Academy of Management Journal, Vol. 38, no.1, pp.24-59.

Northouse, P. G. 2010, “Leadership: theory and practice", Thousand Oaks California: Sage.

Nunnaly, J. 1978, Psychometric Theory, NewYork: McGraw-Monte.

Nyhan, R. C., \& Marlowe, H. A. 199, "Development and psychometric properties of the organizational trust inventory", Evaluation Review, Vol. 21, no.5, pp.614-635.

Pirson, M., \& Malhotra, D. K. 2010, “Antecedents of Stakeholder Trust: What Matters to Whom?”, Fordham University Schools of Business Research Paper, (2010-016).

Podsakoff, P. M. and Organ, D. W. 1986, "Self-reports in organizational research: Problems and prospects", Journal of Management, Vol. 12 , no.4, pp.531-544.

Podsakoff, P. M., MacKenzie, S. B., Lee, J. Y., \& Podsakoff, N. P. 2003, "Common method biases in behavioral research: A critical review of the literature and recommended remedies", Journal of Applied Psychology, Vol. 88, no.5, pp. 879-903.

Reina, D. \& Reina, M. (2007, May 2), "The HR executive's role in rebuilding trust", Human Resource Executive Online. Retrieved from http://www.hreonline.com/HRE/story.jsp? storyld=12160414.

Rousseau, D. M., Sitkin, S. B., Burt, R. S., \& Camerer, C. 1998, "Not so different after all: A cross-discipline view of trust.", Academy of Management Review, Vol.23, no.3, pp.393-404.

Schweizer, K., Moosbrugger, H., \& Schermeller-Engel, K. 2003, "Models for hierarchical structures in differential psychology", Methods of Psychological Research Online, Vol.8, no.2, pp.159-180.

Schoorman, F. D., Mayer, R. C., \& Davis, J. H. 2007, “An integrative model of organizational trust: Past, present, and future”, Academy of Management review, Vol.32, no.2, pp.344-354.

Schyns, B., \& Schilling, J. 2013, "How bad are the effects of bad leaders? A meta-analysis of destructive leadership and its outcomes", The Leadership Quarterly, Vol.24, no:1, pp.138-158.

Shockley-Zalabak, P., Ellis, K., \& Winograd, G. 2000, “Organizational trust: What it means, why it matters”, Organization Development Journal, Vol.18, no.4, 35-48.

Skogstad, A., Einarsen, S., Torsheim, T., Aasland, M. S., \& Hetland, H. 2007, "The destructiveness of laissez-faire leadership behavior", Journal of Occupational Health Psychology, Vol.12, no.1, pp. 80-92.

The Editors of Encyclopædia Britannica (nd). Laissez-Faire. In The New Encyclopedia Britannica. Retrived from http://global.britannica.com/topic/laissez-faire.

Tschannen-Moran, M., \& Hoy, W. 1998, "Trust in schools: A conceptual and empirical analysis", Journal of Educational Administration, Vol.36, no.4, pp.334-352.

Tyler, T. R. 2000, “Social justice: Outcome and procedure", International Journal of Psychology, Vol.35, no.2, pp. 117-125. 